Published in "Dyes and Pigments 83(1): 121-126, 2009"

which should be cited to refer to this work.

\title{
Solid state tautomerism in 2-((phenylimino)methyl)naphthalene-1-ol
}

\author{
Daniela Nedeltcheva ${ }^{a}$, Fadhil S. Kamounah ${ }^{b}$, Laurent Mirolo ${ }^{c}$, \\ Katharina M. Fromm ${ }^{\mathrm{c}}$, Liudmil Antonov ${ }^{\mathrm{a}, *}$ \\ a Institute of Organic Chemistry with Centre of Phytochemistry, Bulgarian Academy of Sciences, Acad. G. Bonchev street, bl. 5, Sofia 1113, Bulgaria \\ ${ }^{\mathrm{b}}$ Department of Science, Systems and Models, Roskilde University, P.O. Box 260, DK-4000 Roskilde, Denmark \\ ${ }^{\mathrm{c}}$ Department of Chemistry, University of Fribourg, Chemin du Musee 9, CH-1700 Fribourg, Switzerland
}

\section{Introduction}

Proton tautomerism plays an important role in many fields of chemistry and biochemistry [1-5]. Molecules giving rise to excited state tautomers by intramolecular proton transfer enjoy applications as laser dyes, in higher energy radiation detectors and molecular memory storage devices, as fluorescent probes and also as polymer protecting agents [6].

The salicylidene anilines (similar to compound $\mathbf{1}$ in the scheme below), being relatively simple in structure, are suitable model compounds for the study of the intramolecular proton transfer, and have therefore attracted considerable attention from both experimental [7-9] and theoretical $[9,10]$ points of view. The proportioning between the tautomeric forms (enol $\mathbf{E}$ and keto $\mathbf{K}$ ), which strongly depends on the conditions of the experimental/theoretical measurements, is the key moment in all investigations.

The measurements are extended from an isolated molecule in vacuum (quantum chemical calculations $[9,10]$ and mass spectrometry [11,12]) through less (UV-Vis spectroscopy $[9,12]$ ) or more (NMR $[8,12,13])$ concentrated solution in various solvents to solid

\footnotetext{
* Corresponding author.

E-mail address: lantonov@orgchm.bas.bg (L. Antonov).

URL: http://www.orgchm.bas.bg/ lantonov
}

state X-ray structure determination [14]. However, the prediction of the relative stability of the tautomers by means of quantum chemical calculations depends strongly on the level of theory (methods and basis sets, solvation models, etc.) used and requires experimental results to prove theoretical findings. Unfortunately, due to different experimental conditions and assumptions in the models for data processing, optical and NMR spectroscopy cannot guarantee the full reliability of the experimentally obtained tautomeric constants $\left(K_{\mathrm{T}}=[\mathbf{K}] /[\mathbf{E}]\right)[13,15]$. The concentration difference between UV-Vis and NMR measurements could be considered as a reason for the difference in the obtained tautomeric constants (under the same other experimental conditions like temperature and solvent) [12]. Generally the increase of the concentration from $10^{-5} \mathrm{M}$ to $0.1 \mathrm{M}$ is expected to have an impact on the solute-solute interactions, but the concentration range $10^{-3}-0.1 \mathrm{M}$ is not accessible for the UV-Vis spectroscopy, which is usually used to provide clear evidence for aggregation. Although there are tautomeric Schiff bases reported to aggregate in nonpolar solvents at the concentrations used by UV-Vis spectroscopy [16], such experiments cannot be repeated by NMR due to solubility reasons. Hereby, the solid state X-ray structure determinations remain the method that gives relatively impartial assessment on the tautomerism in a particular compound and the obtained structural parameters can be used to test the results from the quantum-chemical structure optimizations. 
The aim of the current study is to describe for the first time the crystallographic structure of $\mathbf{1}$ in the solid state (which could be considered as a border case of very concentrated solution in respect of increased solute-solute interactions) and to compare the obtained results for the tautomeric ratio with previous spectral data. At the same time the determined crystal structure will be compared with the structure determined by quantum chemical structure optimization.

\section{Experimental}

\subsection{Synthesis of of 2-((phenylimino)methyl)naphthalene-1-ol}

1-Hydroxy-2-naphthaldehyde, aniline, p-toluenesulphonic acid and absolute ethyl alcohol were of commercial grade (Aldrich) and were used as received. Melting points were determined using a Gallenkamp MF-370; ${ }^{1} \mathrm{H}$ and ${ }^{13} \mathrm{C}$ NMR spectra were recorded on a Varian Mercury 300 spectrometer (300 MHz for ${ }^{1} \mathrm{H}$ NMR and $75 \mathrm{MHz}$ for ${ }^{13} \mathrm{C} \mathrm{NMR}$ ) in $\mathrm{CDCl}_{3}$ using tetramethyl silane (TMS) as internal reference. Fast-atom bombardment (FAB) mass spectra were recorded on a Jeol JMS-HX 110A mass spectrometer.

A solution of 1-hydroxy-2-naphthaldehyde (1.7 g, $10 \mathrm{mmol})$, aniline $(0.94 \mathrm{~g}, 10 \mathrm{mmol})$ and a catalytic amount of p-toluenesulphonic acid (15 mg) in absolute ethyl alcohol $(50 \mathrm{ml})$ was treated at room temperature with dry blue silica crystals $(1.0 \mathrm{~g})$. The mixture was refluxed for $2 \mathrm{~h}$, cooled to ambient temperature and diluted with dichloromethane $(30 \mathrm{ml})$ and filtered. The filtrate was evaporated to dryness in vacuum and the orange solid residue was recrystallized from petroleum ether $\left(60-80^{\circ} \mathrm{C}\right)$ and left at $-18^{\circ} \mathrm{C}$ to give orange crystals ( $1.96 \mathrm{~g}, 80 \%$ yield), m.p. $78-79{ }^{\circ} \mathrm{C} .{ }^{1} \mathrm{H}$ NMR $\left(300 \mathrm{MHz}, \mathrm{CDCl}_{3}\right): \delta 6.99(\mathrm{~d}, 8.7 \mathrm{~Hz}, 1 \mathrm{H}), 7.12(\mathrm{~d}, 9.0 \mathrm{~Hz}, 1 \mathrm{H}), 7.28$ (m, 3H), $7.44(\mathrm{~m}, 3 \mathrm{H}), 7.46(\mathrm{~m}, 1 \mathrm{H}), 7.64(\mathrm{~d}, 7.8 \mathrm{~Hz}, 1 \mathrm{H}), 8.37(\mathrm{~d}$, $6.3 \mathrm{~Hz}, 1 \mathrm{H}), 4.46(\mathrm{~d}, 7.8 \mathrm{~Hz}, 1 \mathrm{H}), 14.86(\mathrm{~s}, 1 \mathrm{H}) ;{ }^{13} \mathrm{C}$ NMR $(100 \mathrm{MHz}$, $\left.\mathrm{CDCl}_{3}\right): \delta 110.8,116.9,119.2,124.9,125.4,126.1,127.3,127.5,128.2$, 129.6, 130.1, 136.9, 142.8, 155.8, 172.3; $\mathrm{m} / z$ (FABMS): 247.3.

\subsection{X-ray measurements}

Crystal data of 1: monoclinic, $P 2_{1} / \mathrm{c}$ (No. 14$), a=14.8460(9)$, $b=7.3210(4)$ and $c=12.6270(10) \mathrm{X}, b=114.332(5) \mathrm{A}$. $V=1250.49(14) \mathrm{X}^{3}, Z=4, d=1.313 \mathrm{Mg} \mathrm{m}^{-3}, 2570$ reflections collected, 1776 unique $\left(R_{\text {int }}=0.0738\right), R_{1}=0.0444(I>2 \mathrm{~s}(\mathrm{I}))$, $w R_{2}=0.1118$ (all data).

Crystal data were collected at $200 \mathrm{~K}$ on an STOE IPDS II using Mo $\mathrm{K}_{\mathrm{a}}$ radiation with graphite monochromator. The structures were solved using the program SIR-2004 [17]. The refinement and all further calculations were carried out using SHELXL-97 (see references [18]). The non-H atoms were refined anisotropically and the hydrogen atoms were located and refined. The Diamond program was used for the graphical representations of the structure.

\subsection{UV-vis spectral measurements and data processing}

The absorption spectra of $\mathbf{1}$ in solution were recorded on a JASCO V-570 UV-Vis-NIR spectrophotometer equipped with a Julabo ED5 thermostat (precision $1{ }^{\circ} \mathrm{C}$ ) at room temperature $\left(20^{\circ} \mathrm{C}\right)$ according to the previously described methodology $[12,15]$. The used solvents were of spectral grade.

The recorded spectral data sets with different tautomeric ratios were processed by the Fishing-Net Algorithm, implemented in the MULTIRES software for quantitative analysis of undefined mixtures [19]. The mathematical background of the procedure was described elsewhere [20]. The correct positions of the individual sub-bands in the spectra were determined by using second derivative spectroscopy [15].

The diffuse reflectance solid state spectrum of 1 was recorded by using ILN-472 large integrating sphere attachment for JASCO V-570 UV-Vis-NIR spectrophotometer.

\subsection{Quantum chemical calculations}

$A b$ initio $\mathrm{HF} / 6-31 \mathrm{G}^{* *}$ calculations were performed by using the Gaussian 03 program suite [21]. This level of theory presents an acceptable compromise between the computing costs and accordance with the experimental results [22]. The well known weakness of the HF method is the neglect of electron correlation, but it is also quite common that basis set incompleteness introduces errors opposite to that, leading in some cases to fortuitously good HF results with medium basis sets [23].

The tautomeric structures shown in Scheme 1 and their dimers were optimized without restrictions (unless otherwise stated) and then were characterized as true minima by vibrational frequency calculations. For comparison reasons the individual tautomers were optimized by using $6-311++\mathrm{G}^{* *}$ basis set as well.

\section{Results and discussion}

The absorption spectra of $\mathbf{1}$ shown in Fig. 1 clearly depict the crucial importance of the solvent on the position of the tautomeric equilibrium. Since the enol form absorbs at $383 \mathrm{~nm}$, it is evident that in nonpolar solvents, like cyclohexane and $\mathrm{CCl}_{4}, \mathbf{1 E}$ dominates ( $K_{\mathrm{T}}=0.17$ and 0.22 respectively). The addition of polar solvents increases the proportion of the keto form, giving rise to the complex band at $450 \mathrm{~nm}$, which consists of sub-bands at 430,454 and $484 \mathrm{~nm}$. The tautomeric constants in $\mathrm{CHCl}_{3}$ and DMSO are 0.72 and 0.85 correspondingly, which is surprising taking into account the different proton acceptor/donor properties of these solvents. However, it has been proven by linear solvation energy relationship analysis [9] and by quantum chemical calculations [24] that due to the substantial strength of the intramolecular hydrogen bonding in the Schiff bases their interaction with proton acceptor solvents (like DMSO) is limited and the observed limited (in comparison with $\mathrm{CHCl}_{3}$ ) changes result only from the net polarity of DMSO.

The solid state spectrum of $\mathbf{1}$ is also shown in Fig. 1. In consists of a structureless red tail, which contains a band with a maximum at $\sim 695 \mathrm{~nm}$ (according to the second derivative spectra), and two complex bands around $400 \mathrm{~nm}$ and around $500 \mathrm{~nm}$. By analogy with 4-((phenylimino)methyl) naphthalene-1-ol [25] the band at $500 \mathrm{~nm}$ and the red tail show existence of associates of the keto form. It is evident that the band at $500 \mathrm{~nm}$ contains except the

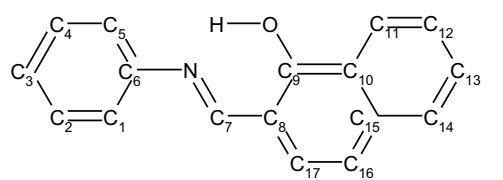

$1 E$<smiles>O=C1C(=CNc2ccccc2)C=C[As]2C=CC=CC12</smiles>

$1 \mathrm{~K}$

Scheme 1. Tautomeric equilibrium in $\mathbf{1}$. 


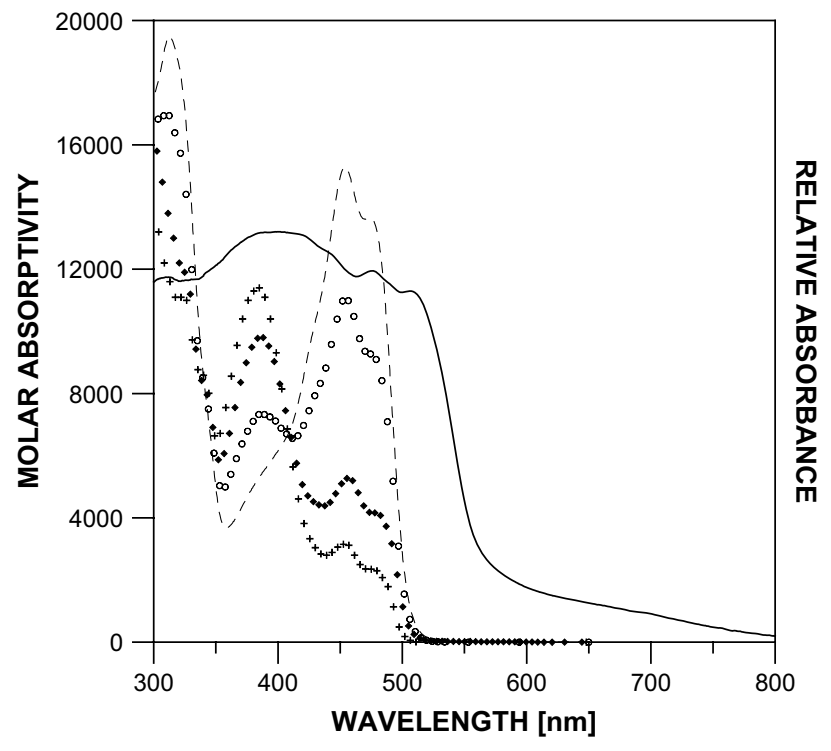

Fig. 1. Absorption spectra of $\mathbf{1}$ in solution - cyclohexane (+++), $\mathrm{CCl}_{4}$ (rhombs), $\mathrm{CHCl}_{3}$ (circles), DMSO (dashes) and in solid state (solid line, right Y-scale).

sub-bands typical for the monomer keto form (420, 443 and $476 \mathrm{~nm}$ ), one additional slightly red shifted band at $512 \mathrm{~nm}$. According to the molecular exciton theory [26] it could be attributed to head-to-tail aggregation and the slight red shift indicates a low level of association. At the same time these low level associates interact with each other, which leads to the appearance of the wide tail at $695 \mathrm{~nm}$. Unfortunately the structure of the enol band at $400 \mathrm{~nm}$ is very complex and cannot be clarified by derivative spectroscopy, which does not allow conclusions to draw about the aggregation of the enol tautomer. Evidently the complex structure of the solid state spectrum does not allow a quantitative estimation of the position of the tautomeric equilibrium.

Single crystals of $\mathbf{1}$ were obtained by slow evaporation of the mother solutions, respectively by recrystallization from the used solvent. Compound $\mathbf{1}$ crystallizes in the monoclinic space group $\mathrm{P} 2{ }_{1} / \mathrm{c}$ (No. 14) with one molecule per asymmetric unit. As the hydrogen atoms could be attributed in the Fourier map, we are able to discuss the proportion of the two tautomers. Indeed, the compound seems to be in an equilibrium between the keto and the enol form, and in which the keto form is much more favored. We found that the hydrogen atom position is split over two positions, being found at $85 \%$ on the nitrogen and at $15 \%$ on the oxygen atom, respectively (which corresponds to $K_{\mathrm{T}}=5.7$ and $\Delta G=-0.7 \mathrm{kcal} /$ $\mathrm{mol}$ at $200 \mathrm{~K}$ ). The electron density map (Fig. 2a) illustrates this finding, showing electron density in between the oxygen and nitrogen atom of the same molecule. The most important bond lengths and angles are listed in Table 1.

In order to compare the bond lengths found in compound $\mathbf{1}$ with other molecules containing similar functional groups, a search in the Cambridge Structural Database (CSD) was performed. The results of this search are listed in Fig. S1. The comparison with the mean bond lengths of similar molecules clearly tends to confirm our hypothesis that $\mathbf{1}$ is preferentially found in its keto form.

The molecules stack in the solid state structure in a fish-bone like arrangement (Fig. 2b, right), forming pairs two-by-two (dimers in wider understanding). Among these pairs of molecules, a headto-tail packing is observed, with offset $\pi$-stacking at ca. $3.5 \AA$ between the rings $C_{1}-C_{6}$ and $C_{10}-C_{15}$ of two parallel molecules. Two parallel pairs are then inclined almost perpendicularly to the next pair of molecules, allowing for strong edge-to-face $\pi$-interactions between $\mathrm{H}_{4}$ and $\mathrm{H}_{11}$ of one molecule, and the rings $\mathrm{C}_{10}-\mathrm{C}_{15}$ and $\mathrm{C}_{1-}$ $\mathrm{C}_{6}$, respectively, of another molecule (see review by Steiner [27]). The $\mathrm{H}_{4}-\mathrm{C}$ and $\mathrm{H}_{11}-\mathrm{C}$ distances vary between 2.89 and $3.20 \AA$, respectively 2.94 and $3.24 \AA$, but if measured between $\mathrm{H}$ and the mean plane of the rings, those distances are equal to 2.70 and 2.75 A respectively. Furthermore to these interactions, Fig. $2 \mathrm{~b}$ (left) shows a hydrogen bonding stabilizing weakly the oxygen from another molecule, favoring also the keto form. It is a weak interaction with an $\mathrm{H}_{16}-\mathrm{O}$ distance of ca. $2.5 \AA$ and a $\mathrm{C}_{16}-\mathrm{H}_{16}-\mathrm{O}$ angle of ca. $133.7^{\circ}$.

The crystallographic data are compared with the optimized (HF/ $6-31^{* *}$ and $\mathrm{HF} / 6-311++\mathrm{G}^{* *}$ ) individual tautomers in Table 1 . It is evident that the change of the basis set does not change substantially the geometries and there is reasonable agreement between the quantum chemical results (bonds and angles in the tautomeric fragment) and the experimental structure data. As can be seen from the Table, the experimental bond lengths and angles lie between the calculated values for $\mathbf{E}$ - and $\mathbf{K}$-form, which is in accordance with the fact that the tautomeric equilibrium exists even in the solid state. Reasonably the length of the bonds forming the tautomeric fragment, namely $\mathrm{N}-\mathrm{C}_{7}, \mathrm{C}_{7}-\mathrm{C}_{8}, \mathrm{C}_{8}-\mathrm{C}_{9}$ and $\mathrm{C}_{9}-\mathrm{O}$, are most sensitive and can be used as indicators for the position of the tautomeric equilibrium in the solid state. As seen the experimental values lie nearer to the calculated values for the keto form, which is in accordance with the tautomeric ratio determined by the X-ray measurements.

According to the quantum chemical calculations the individual tautomers are predicted to be nonplanar in respect of the phenyl ring, which corresponds to the general experimentally and theoretically supported concept for twisting around the $\mathrm{N}$-phenyl bond [28] in solution. The corresponding $\Delta G$ values at room temperature are $1.0 \mathrm{kcal} / \mathrm{mol}$ (cyclohexane) and $0.89\left(\mathrm{CCl}_{4}\right) \mathrm{kcal} / \mathrm{mol}$, which reasonably well reproduce the $\Delta \Delta G$ quantum chemical results for isolated molecules in the gas phase (Fig. 3). Probably in the solid state due to the stacking of the molecules they are forced to planarise as has been reported for some Schiff bases [28a,29]. It should be noted that the constrained planarity in the quantum chemical calculations gives a rise in the total energy for $\mathbf{1 E}$ by $1.4 \mathrm{kcal} / \mathrm{mol}$, while in the case of $1 \mathrm{~K}$ the increase is $0.2 \mathrm{kcal} / \mathrm{mol}$, changing the relative energy from 0.9 (enol form more stable) to $-0.3 \mathrm{kcal} / \mathrm{mol}$ (1K more stable), which by itself does not describe the substantial predominance of the keto tautomer in the solid state.

Obviously these two possible assumptions - planarity and nonplanarity, give different opportunities for further description of the effects of association. Constrained planarity could be used for an explanation of aggregation in the solid state, while the natural nonplanarity could be useful for clarifying the solute-solute interactions in concentrated solutions in nonpolar and proton acceptor solvents. Both concepts are demonstrated in Fig. 3.

The agreement between the $\Delta G$ values in nonpolar solvents and the quantum chemical calculations at $\mathrm{HF} / 6-31 \mathrm{G}^{* *}$, noted above, allows this level of theory to be used for the further calculation of the tautomeric dimers. In the non constrained optimization two possible dimer aggregates have been found. In both cases (E and $\mathbf{K}$ ) the structures of the most stable dimers differ substantially from the crystallographic determination. Most probably due to the nonplanarity (steric hindrance caused by the phenyl rings), the dimer structures similar to these seen in Fig. $2 \mathrm{~b}$ are not favored. In the case of the gas phase the inter-molecular hydrogen bonding between the oxygen (as seen in Fig. 3 right) and the azomethine hydrogen are preferred (with distance of $2.3 \AA$ in the keto dimer and $3.1 \AA$ An the enol one). However, the aggregation changes the overall picture of the tautomeric equilibrium from more stable enol form in isolated molecules to more stable keto dimer, which could correspond to the experimental findings in concentrated solutions. 


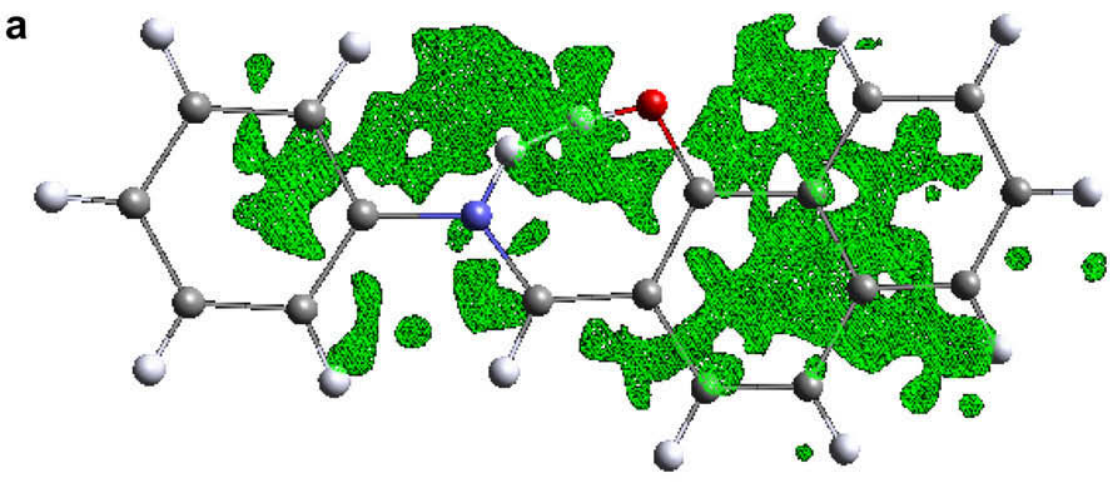

b
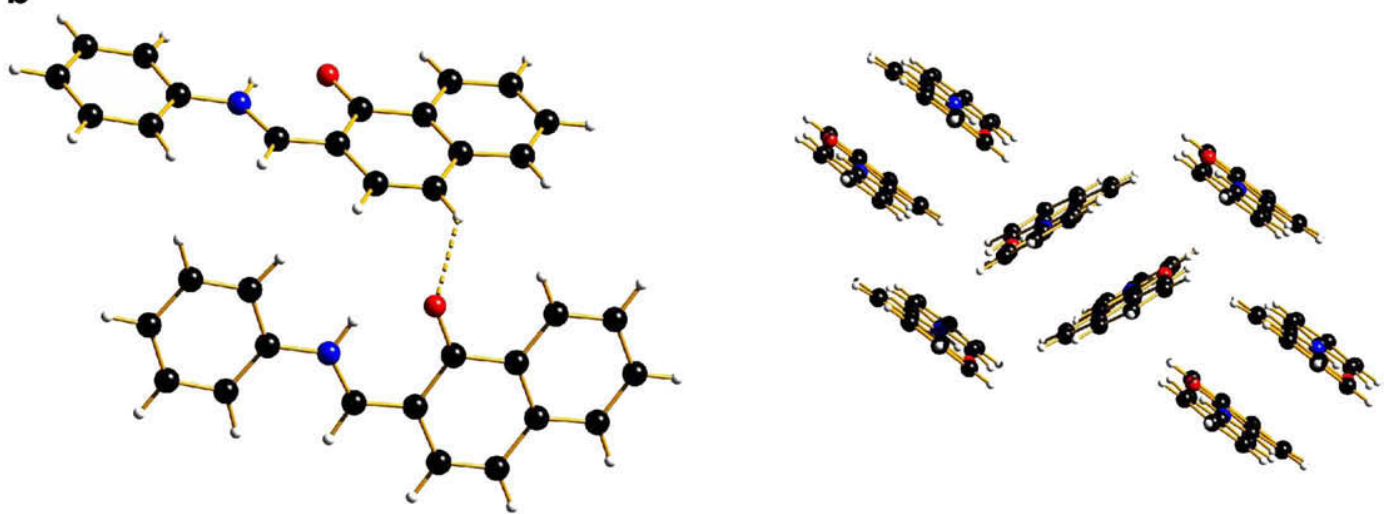

Fig. 2. a) Density map of the molecule with hydrogen occupying both positions; b) View of some inter-molecular interactions with H-bonding on the oxygen (left) and p-stacking in the crystal (right).

$\frac{0}{0}$

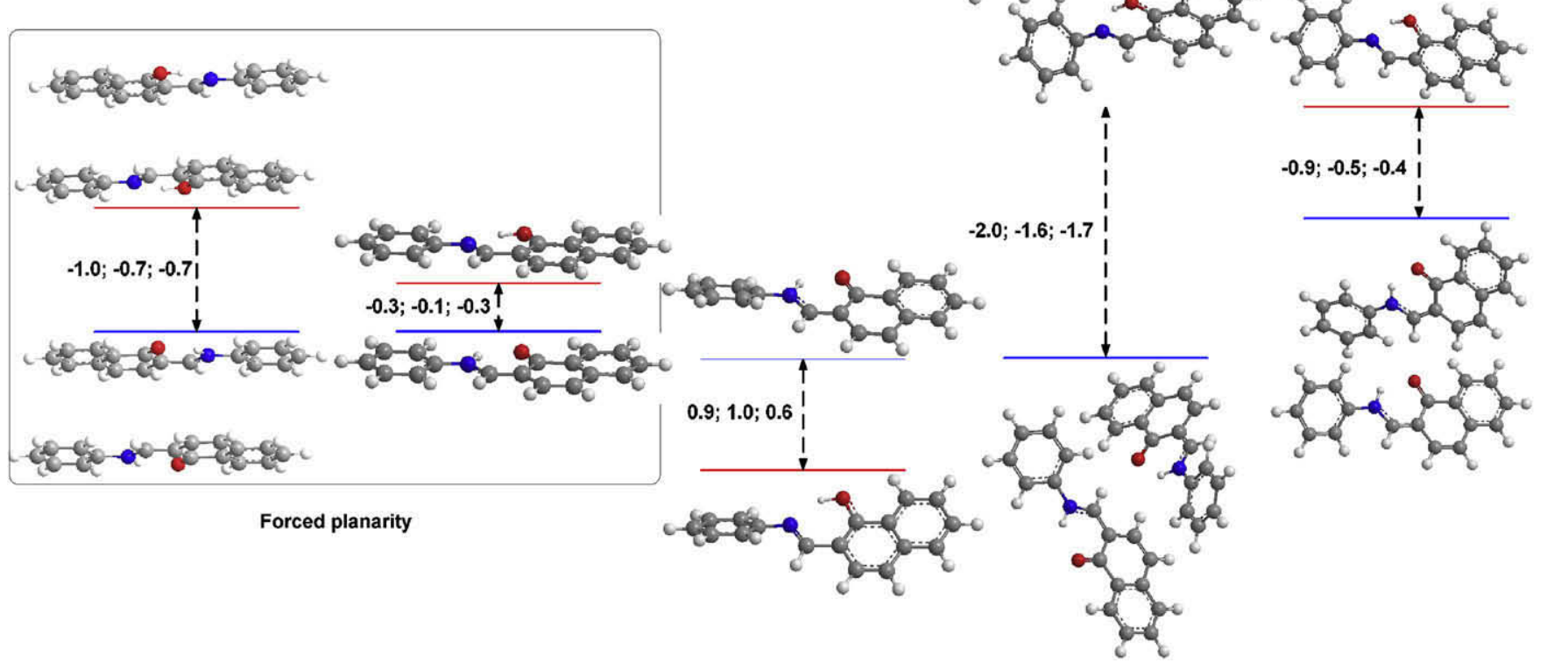

Fig. 3. Relative stability of the monomer and dimer tautomers as predicted by HF/6-31G ${ }^{* *}$ calculations for gas phase with (left) and without (right) constrained planarity. The corresponding values ( $\Delta E ; \Delta E+\mathrm{ZPE} ; \Delta \Delta G$ ) are given in $\mathrm{kcal} / \mathrm{mol}$. The negative values correspond to more stable keto form and vice versa. 
Table 1

Experimental structural data and optimized geometries of both tautomers.

\begin{tabular}{|c|c|c|c|c|c|c|c|c|c|c|c|c|c|}
\hline \multirow[t]{3}{*}{ Structure } & \multicolumn{2}{|c|}{ Distance [Å] } & \multicolumn{5}{|c|}{ Bond length $[\AA ̊]$} & \multicolumn{5}{|c|}{ Angle [deg] } & \multirow{3}{*}{$\frac{\text { Torsion angle [deg] }}{\mathrm{C}_{5}-\mathrm{C}_{6}-\mathrm{N}-\mathrm{C}_{7}}$} \\
\hline & $\mathrm{N}-\mathrm{H}$ & $\mathrm{O}-\mathrm{H}$ & $\mathrm{O}-\mathrm{N}$ & $\mathrm{N}-\mathrm{C}_{7}$ & $C_{7}-C_{8}$ & $\mathrm{C}_{8}-\mathrm{C}_{9}$ & $\mathrm{C}_{9}-\mathrm{O}$ & $\mathrm{C}_{6}-\mathrm{N}-\mathrm{C}_{7}$ & $\mathrm{~N}-\mathrm{C}_{7}-\mathrm{C}_{8}$ & $C_{7}-C_{8}-C_{9}$ & $\mathrm{C}_{8}-\mathrm{C}_{9}-\mathrm{O}$ & $\mathrm{C}_{9}-\mathrm{O}-\mathrm{H}$ & \\
\hline & & & & & & & & & & & & $\mathrm{C}_{7}-\mathrm{N}-\mathrm{H}$ & \\
\hline 1E HF/6-31G ${ }^{* * a}$ & - & 0.957 & 2.678 & 1.264 & 1.460 & 1.381 & 1.324 & 123.4 & 123.2 & 122.3 & 122.8 & $\begin{array}{l}109.2 \\
-\end{array}$ & 0.0 \\
\hline 1E HF/6-31G** & - & 0.957 & 2.683 & 1.264 & 1.460 & 1.380 & 1.325 & 120.4 & 123.6 & 122.1 & 122.9 & $\begin{array}{l}109.6 \\
-\end{array}$ & -138.2 \\
\hline 1E $\mathrm{HF} / 6-311++\mathrm{G}^{* *}$ & - & 0.955 & 2.687 & 1.261 & 1.461 & 1.379 & 1.324 & 120.3 & 123.6 & 122.2 & 122.9 & $\begin{array}{l}109.7 \\
-\end{array}$ & -136.7 \\
\hline 1 X-ray & 0.917 & 0.998 & 2.603 & 1.314 & 1.404 & 1.439 & 1.266 & 126.5 & 123.1 & 120.2 & 122.8 & $\begin{array}{l}104.5 \\
116.4\end{array}$ & 179.0 \\
\hline 1K HF/6-311++G ${ }^{* *}$ & 1.000 & - & 2.681 & 1.330 & 1.367 & 1.461 & 1.215 & 125.9 & 126.4 & 120.9 & 122.2 & $\begin{array}{c}- \\
115.1\end{array}$ & -153.0 \\
\hline 1K HF/6-31G & 1.001 & - & 2.675 & 1.331 & 1.367 & 1.461 & 1.220 & 126.1 & 126.2 & 120.8 & 122.4 & 114.7 & -152.9 \\
\hline 1K HF/6-31G ${ }^{* a}$ & 1.001 & - & 2.676 & 1.331 & 1.367 & 1.462 & 1.219 & 127.8 & 126.0 & 121.0 & 122.3 & $\begin{array}{c}- \\
114.0\end{array}$ & 0.0 \\
\hline
\end{tabular}

a Constrained planarity.

Unfortunately there are only two values of $K_{\mathrm{T}}$ determined by NMR 0.95 [8a] and 2.24 [8b]. The fact that in both cases $\mathrm{CDCl}_{3}$ has been used as a solvent and the different approximations used in the tautomeric constant estimation does not allow an explicit conclusion that the higher tautomeric constants result from the higher concentration in the NMR measurements.

The constrained planarity describes the dimers (Fig. 3, left) very similar to those observed by the X-ray measurements (Fig. 2b, right). The head-to-tail packing is reproduced, with offset $\pi$ stacking at ca. $3.5 \AA$ between the rings $C_{1}-C_{6}$ and $C_{10}-C_{15}$ of two parallel molecules, essentially the same as in the solid state. However, the simplicity of the theoretical model (only two dye molecules and lack of additional packing) allows the molecules in the dimer to be displaced sideways (as the angle $\mathrm{O}-\mathrm{C}_{17}-\mathrm{O}$ is changed from $89.3^{\circ}$ in solid state to $132.7^{\circ}$ in the theoretical calculation). The calculated $\Delta \Delta G$ value of $-0.7 \mathrm{kcal} / \mathrm{mol}$ corresponds to $K_{\mathrm{T}}=3.45$ at $298 \mathrm{~K}$, which agrees with the crystallographic results taking the temperature difference into account $\left(K_{\mathrm{T}}=5.7\right.$ and $\Delta G=-0.7 \mathrm{kcal} / \mathrm{mol}$ at $200 \mathrm{~K}$ ). Obviously the shift of the tautomeric equilibrium towards the keto form in solid state is caused by both forced planarization of the molecules and aggregation. Consequently, instead of the simplicity of the theoretical model, it predicts correctly the tendency of change in the position of the tautomeric equilibrium towards the keto form as shown by the crystallographic data (Fig. 2) and the solid state absorption spectra (Fig. 1).

\section{Conclusions}

The X-ray structure of 2-((phenylimino)methyl)naphthalene-1-ol shows a fish-bone like arrangement, forming pairs two-by-two. The solid state structural data have been reproduced by $a b$ initio calculations. They show that the shift of the tautomeric equilibrium from the enol form in solution to the keto form in solid state is caused by both forced planarization of the molecules and aggregation. Consequently, instead of the simplicity of the theoretical model, it predicts correctly the tendency of change in the position of the tautomeric equilibrium towards the keto form as shown by the crystallographic data and the solid state absorption spectra.

\section{Acknowledgements}

The financial support from The Swiss National Science Foundation (JRP IB7320-110961/1) is gratefully acknowledged.

\section{References}

[1] Hynes JT, Klinman JP, Limbach H-H, Schowen RL, editors. Hydrogen transfer reactions. Weinheim: Wiley-VCH; 2006.

[2] Muller A, Rataiczak H, Junge W. Electron and proton transfer in chemistry and biology. In: Diemann E, editor. Studies in physical and theoretical chemistry. Amsterdam: Elsevier; 1992.

[3] Elsaesser T, Bakker HJ, editors. Ultrafast hydrogen bonding dynamics and proton transfer processes in condensed phase. Dordrecht: Kluwer Academic Publishers; 2002.

[4] Sugawara T, Takasu I. Adv Phys Org Chem 1999:32:219-65.

[5] Zollinger H. Color chemistry: syntheses, properties \& applications of organic dyes \& pigments. Weinheim: VCH; 1991

[6] Nagaoka S, Hirota N, Sumitani M, Yoshira K. J Am Chem Soc 1983;105:4220-6; Sytnik A, Del Valle JC. J Phys Chem 1995;99:13028-32;

Schmidt GMJ. In: Ginsburg D, editor. Solid state photochemistry. Weinheim: VCH 1976:

Sakai KI, Ichikawa M, Taniguchi Y. Chem Phys Lett 2006;420:405-9; Nishiya T, Yamauchi S, Hirota N, Baba M, Hanazaki I.J Phys Chem 1986;90:5730-5 Park S, Kim S, Seo J, Park SY. Macromol Res 2008;16:385-95.

[7] Kownacki K, Mordzinski A, Wilbrandt R, Grabowska A. Chem Phys Lett 1994;227:270-6.

Grabowska A, Kownacki K, Kaczmarek L. J Lumin 1994;60-61:886-90;

Alarcón SH, Pagani D, Bacigalupo J, Olivieri AC. J Mol Struct 1999;475:233-40; Joshi H, Kamounah FS, van der Zwan G, Gooijer C, Antonov L. JCS Perkin Trans 2001;2:2303-8:

Antonov L, Fabian WMF, Nedeltcheva D, Kamounah FS. JCS Perkin Tran 2000;2:1173-9;

Ziolek M, Burdzinski G, Filipczak K, Karolczak J, Maciejewski A. Phys Chem Chem Phys 2008:10:1304-18;

Alarcon SH, Olivieri AC, Sanz D, Claramunt RM, Elguero J.J Mol Struct 2004;705:1-9.

[8] (a) Dudek GO, Dudek EP. J Am Chem Soc 1966;88:2407-8; (b) Salman SR, Kamouhan FS. Spectroscopy 2003;17:747-52

[9] Fabian WMF, Antonov L, Nedeltcheva D, Kamounah FS, Taylor PJ. J Phys Chem 2004:108:7603-12;

Antonov L, Fabian WMF, Taylor PJ. J Phys Org Chem 2005;18:1169-75.

[10] Zgierski M, Grabowska A. J Chem Phys 2000;113:7845-52; Kletski M, Milov A, Metelisa A, Knyazhansky M. J Photochem Photobiol 1997; 110A:267-70

Nagy PI, Fabian WMF. J Phys Chem 2006;110B:25026-32;

Filarowski A, Kochel A, Kluba M, Kamounah FS. J Phys Org Chem 2008;21:939-44.

[11] Salman SR, Kamounah FS. Spectrosc Lett 2002;35:327-35.

[12] Nedeltcheva D, Antonov L, Lycka A, Damyanova B, Popov S. Curr Org Chem 2009;13:217-39.

[13] Claramunt RM, Lopez C, Santa Maria MD, Sanz D, Elguero J. Prog NMR Spectrosc 2006;49:169-206.

[14] Iglesias AL, Aguirre G, Somanathan R, Parra-Hake M. Acta Crystallographica 2006;E62:0390-2;

Akitsu T, Einara Y. Acta Crystallographica 2006;E62:04315-7; 
Bertolasi V, Pretto L, Ferretti V, Gilli P, Gilli G. Acta Crystallographica 2006;B62:1112-20;

Bertolasi V, Pretto L, Gilli G, Gilli P. Acta Crystallographica 2006;B62:850-63. Liu XG, Feng Y-Q, Liang Z-P, Wang W. Acta Crystallographica 2005;E61:03857-8; Schmidt MU, Bruning J, Wirth D, Bolte M. Acta Crystallographica 2008;C64:0474-7;

Ogawa K, Kasahara Y, Ohtani Y, Harada J. J Am Chem Soc 1998;120:7107-8.

115] Antonov L, Nedeltcheva D. Chem Soc Rev 2000;29:217-27.

[16] Ogawa K, Harada J, Fujiwara T, Yoshida S. J Phys Chem 2001;105A:3425-7.

[17] Sir2004 Burla MC, Caliandro R, Camalli M, Carrozzini B, Cascarano GL, et al. J Appl Cryst 2005;38:381-8.

[18] Sheldrick GM. SHELX-97, Program for crystal structure refinement. Gittingen: University of Gittingen; 1997.

[19] http://www.orgchm.bas.bg/ lantonov/FiNAl.htm.

[20] Antonov L, Petrov V. Anal Bioanal Chem 2002;374:1312-7.

[21] Frisch MJ, Trucks GW, Schlegel HB, Scuseria GE, Robb MA, Cheeseman JR, et al. Gaussian 03, revision B.01. Wallingford CT: Gaussian, Inc.; 2003.

[22] Antonov L, Kawauchi S, Satoh M, Komiyama J. Dyes Pigments 1998;38:157-64; Antonov L, Kawauchi S, Satoh M, Komiyama J. Dyes Pigments 1999;40:163-70.

[23] Sheikhshoaie I, Fabian WMF. Curr Org Chem 2009;13:147-71.
[24] Nedeltcheva D. Antonov L. J Phys Org Chem, 2009;22:274-81.

[25] Kamounah FS, Antonov L, Petrov V, van der Zwan G. J Phys Org Chem 2007;20:313-20.

[26] UV-vis spectroscopy is especially suitable for study of the aggregation of dyes since the formation of dimers (or higher order associates) causes symmetrical splitting of the monomer absorption maxima (the higher extent of aggregation causes larger shift of the new bands in respect of the momener ones; in addition the intensity of these new bands could be used as crude indication of the extent of dye to dye interaction). For details see: Kasha M, Rawls HR, ElBayomi MA. Pure Appl. Chem. 1965; 11:371-92; Antonov L, Gergov G, Petrov V, Kubista M, Nygren J. Talanta 1999; 49: 99-106; D'llario L, Martinelli A. Modelling Simul. Mater. Sci. Eng. 2006; 14: 581-95; Wurthner F, Yao S, Debaerdemaeker T, Wortmann R. J. Am. Chem. Soc. 2002; 124:9431-47.

[27] Steiner T. Angew Chem Int Ed 2002;41:48-76.

[28] (a) Morley JO. J Mol Struct 1995;340:45-50;

(b) Stoyanov S, Dobrev A, Antonov L. Monatsh Chemie 1994;125:259-66. and the references cited therein.

[29] Flower KR, Pritchard RG, Warren JE, Eur J Inorg Chem 2003:1929-38. Flower KR, Howard VJ, Pritchard RG, Warren JE. Organometallics 2002;21: $1184-9$. 